\title{
A Study on the Classification and Protection of Yugur Traditional Folk
}

\section{Songs Based on Experimental Phonetics}

\author{
Shiliang Lyu ${ }^{1, a,}$ \\ ${ }^{1}$ Key Laboratory of National Language Intelligent Processing, GansuProvince,Northwest MinZu \\ University, Lanzhou,China \\ ashilianglv@126.com
}

Keywords:Yugur traditional folk songs, oral culture, inheritance and protection

\begin{abstract}
Yugur traditional folk song is the main form and carrier of folk culture of the Yugur culture. Because there is no existing Yugur character, and fewer and fewer people use the Yugur language.Yugur traditional folk heritage is facing great difficulties. In this paper,mainly on the classification of Yugur traditional folk songs as the research content. Through different folk songs classification to provide the reference forthe protection of Yugur traditional folk songs, and provide effective suggestions for the Yugur traditional folk songs inherit.
\end{abstract}

\section{Introduction}

Yugur is one of the oldest ethnic groups in China, located in the middle of the Hexi Corridor and the Qilian Mountains region, mainly in Gansu Sunan and Suzhou District Jiuquan City HuangnipuYugur Township. The minority is endemic to Gansu, but also China less populous ethnic groups.According to China's sixth census statistics show that as of 2010, the current population is 14378 people, belong to the minority[1].

Due to historical reasons and population movements, while national integration, the integration of language Yugur language had a profound impact. Yugur mainly by the integration of Turkic and Mongolian language branchtogether. Today, the Yugur use Chinese, also used two kinds of native language, respectively, of Eastern yugur and Western Yugur language. Because geographical and other reasons, the situation of Yugur language is more complicated and very few people use Yugur language.Eastern language belongs to the Altaic family, with the Mongolian, Dongxiang language closely related. West language belongs to Altaic Turkic, with Uighur, Kazakh and other closely related.The Yugur character has been lost, the widespread use of existing voice recording Chinese characters. Yugur Language learning materials mainly used IPA or Latin alphabet transliteration way to record voice[2]. In Yugur folk songs, preserves phonetic features, and is the carrier of cultural inheritance.

Yugur folk songs has a unique style and a wealth of genres, reflecting the strong ethnic characteristics. The folk songs with unique original ecological way to record the songs, cultural and historical changes, and sung with the Yugur people's thoughts and feelings and mentality, plays a very important role in the national culture. Yugur folk songs or the study of ancient North China minority folk songs, especially Mongolian, Turkic nomads and folk history and culture. And it is the basis of the protection and excavation of the folk songs of the minorities in the north of China.Previous studies have mostly used audio and video mode, it is difficult to restore the singing style of folk songs and respiratory characteristics, which is the difficulty of oral culture research, 
and not easy to study on classification of folk songs[3].

This paper will be based on the current research on the combination of Yugur Language Features and language style, research on the classification of Yugur traditional folk songs, which is used for experimental phonetics research.Purpose is to provide a classification method for the study of Yugur folk songs, and provide reference for the study of other ethnic and oral cultural tradition.

\section{The style of Yugur folk songs}

Regional style characteristics.Yugur folk music style loud and clear, beautiful, melody long, lively rhythm, with distinctive ethnic characteristics.According to the distribution of Yugur population settlements as well as the different use of language, can be divided folk songs into eastern and Western folk songs.

In the eastern part of Kangletownship as the representative, has bold and heroic spirit, the rich music features of Mongolian folk songs.Western folk songs with Minghua and Dahetownship as the representative of folk songs, deep and flat, inherited the ancient Uighur folk song. Yugur traditional folk songs, is a creation in the Yugur people long nomadic life and singing folk cultural heritage, and contains rich cultural characteristics and ethnic characteristics.

Voice style features. From the two aspects of folk songs rhythm and beat.At the beginning and end of the syllable duration is longer, while in the middle part of the duration is shorter.And influenced by the rhythm, near the end of the syllable position becomes longerand relaxed.This speech style and rhythm of the music on the layout is the most direct form of expression in folk voice variation.From the syllable features, the majority of Western Yugur language accent would fall on the last syllable, speech feature allows Yugur folk songs in rhythm and tempo of voice has an inherent characteristic style.

In Yugur folk songs, is located in front of the syllables of short duration, while the last syllable lasted for a long time, thus expanding the rhythm of the folk form. This rhythm structure is conducive to efforts to strengthen the melody, which can express the characteristics of passionate folk tunes. If the melody is repeated, it can make folk melody compact and full of emotion.

\section{The traditional classification of Yugur folk songs}

Usually, anything can be classified according to a certain aspect of things characteristics of things, any kind of discipline, the research object of its research needs a reasonable classification. The same is true of folk songs, folk songs have different characteristics inherent properties that can be categorized by region, genre, stage and history[4].

The classification of folk songs is closely related to the study of folk songs. With the development of the times and the continuous improvement of the level of the study of folk songs, folk classification has become a matter of growing concern. Folk song classification is an effective means, the purpose of classification is to better research, inheritance and protection of folk songs[5].

Classification according to development stage.According to the different stages of development of Yugur folk songs, it can be divided into four stages. Such as Zhou Hongde (2011) will be divided into the ancient song of Yugur folk songs and traditional folk songs, new folk songs and folk songs of new creation. Ancient song of Yugur folk songs in early sixteenth Century, record the history of our ancestors Yugur culture, because the words lost, lack of research data, can only be inferred according to the limited literature. 
Traditional folk songs stage is the sixteenth century to the 1960s folk songs,and it is also the main research stage, as folk stage has the most traditional culture characteristics of Yugur nationality, folk representative works such as "Huangdaichen" and "Xizhihhazhi".

New folk songs of the 1950s to 1990s, and it was the adaptation and innovation based on Yugur traditional folk musicians finishing on.

The folk songs of new creationare from twentieth Century 90s to now, the Yugur folk songs by creation of music workers. Works in this period mostly reflect the Yugur modern life, but Yugur culture elements less reserved.

Classification according to geography. The geographical classification is divided according to the folk song popular area. Yugur folk songs research scholar Du Yaxiong(1981) according to the living area and the Yugur Language, will be divided Yugur folk songs into the Yugur eastern folk songs and Western songs.Poem for the lyrics of folk songs is called "Yer" in Yugur western region, in the east called the "Dun".

The Western folk songs divided into narrative songs, wedding songs and pastoral.Eastern folk songs are divided into narrative songs, wedding songs, songs of praise and song of praise. The eastern parts of the traditional folk songs are rough, bold.

However, the Western folk song is more gentle and peaceful. Belonging to the "Yer" and "Dun" the rhythm of folk songs is more casual, with the Mongolia tune is more similar, while not belonging to the "Yer" and "Dun" the rhythm of folk songs are more uniform, similar to the short tune of the Mongolian.

Classification according to genre.According to different genres can be divided Yugur folk songs into narrative songs, labor songs and custom songs. The narrative song is also called the historical song or the story song, the lyrics content mainly is the narration.The narrative songhas high research value. Because of the long history of narrative songs, the lyrics have a long history of historical records. The lyrics of voice to retain a lot of ancient Yugur Language Pronunciation, such as the history of the migration process, the origin of Yugur traditional wedding and other custom origin, and about national hero, tribal wars and social life records.

The labor songs according to different types of labor can be divided into the pastoral song, suckle songs and other labor songs. The pastoral song is singing in the grazing time, because the grassland environment, the pastoral song style is melodious, open. The suckle songsis a song tosuckling livestock, such as suckling cattle and sheep. The melody of suckle songs, sweet affectionate euphemism. The dams heard the song can suckler neonate gently.Other types of labor songs, such as mowing song and twisting song, etc. The songs melody is more flexible, the rhythm is clear, also has some meaning of humor.

Custom song is one of the prominent types to the Yugur folk song, which contain a lot of historical and cultural tradition, there are mainly wedding song, toasting song, sacrificial songs, etc., with strong ethnic characteristics. The same as the narrative song, custom song also has high research value, record the history of the Yugur customs.

The local classification method.The local classification method is Yugur folk songs sung in long-term singing, from the folk song singing and content to categorize different folk songs. According to the different forms, the folk song is divided into "tune", "minor", "love song" and "narrative", "wedding song" and other forms. According to the content, the folk song is divided into pastoral, epic, labor songs, praise songs, wedding songs, shaved songs and love songs, etc[6]. 


\section{Thedifficulty of protection of Yugur traditional folk songs}

With the development of the society, Yugur culture and history are also changing. Because the living environment and living conditions improved, and the desire for a new life, traditional culture has been gradually fade. The use of the national language of the Yugur peoples less and less, Yugur folk heritage encountered many problems.

First is the language problem, Yugur words missing and abundant solid language differences in east and west. There are fewer and fewer people in the use of Yugur language, which is not conducive to the study of the folk song. So that some folk song lyrics have been unable to understand.

The second is the geographical factors, because the settlements for pastoral areas Yugur. Traffic is not convenient and living is not concentrated, leading to folk songs is not easy to spread to the outside world. Affected by the geographical environment, the migration of the population also has an impact on the heritage of folk songs.

The third factor is the folk songs inheritor. There are only a few Yugur folk songs inheritor, and by the way of oral cultural heritage. Because the influenced by linguistic and cultural factors, the folk learner difficult to master singing skills and style features.Therefore, In the Yugur traditional folk songs heritage, the most important issue to be resolved is the language problem,the second is the singing style characteristics.

\section{Conclusion}

Yugur traditional folk song has a high cultural value, inheritance and protection of Yugur traditional folk songs play an important role in the study and protection of Yugur culture, is not only the needs of the times, but also the nation's needs.

Same as the other oral cultural heritage method, Yugur traditional folk heritage now mainly adopt the way of oral culture. And is usually a family tradition way, children learn from their elders, is rarely part of teaching through the mentoring relationship.

In the process of learning the Yugur traditional folk songs, the most important thing is to understand the lyrics and mastery of singing techniques, the existing folk heritors limited, most of the folk songs are studied by audio and video materials. Although there are audio and video data, however, using the existing data to learn Yugur traditional folk songs is very difficult,only through acoustic research results such as phonetics, singing to carry on the comprehensive study, to be effective learning folk songs.At the same time of study to providing materials and methods for folk song learners.

According to the classification of folk songs, scholars can collect and sort out folk songs according to different categories. By collection of Yugur traditional folk songs voice acoustics, physiological speech and video signal. Through multiple signal data, the learners can synthesize various kinds of signals to study folk songs singing skills and methods, and master the original features of the pronunciation of the folk songs, so as to achieve the purpose of protecting and inheriting the folk songs.

\section{Acknowledgement}

This research was financially supported by Northwest MinZu University 2016 annual basic scientific research funds of the central university funding projects(Grant NO. 31920160072). 


\section{References}

[1] QianWeidong, SunanYugur Autonomous County Annals,Gansu National Publishing House, 1994.

[2] Chen Zongzhen, Yugur and its language,Journal of xinjiang university, 1977.

[3] Zhou Hongde, A Study on the Succession of Traditional Folk Songs of Yugu Nationality, Master's degree thesis ofNorthwest MinZu University,2011.

[4] Du Yaxiong, The music characteristic of yugur folk songs, Journal of central music college, 1981.

[5] Lang Wenying, The Study of The Yugur Folk Song's Inheritor in ThePerspective of Ethnoiogy, Master's degree thesis ofNorthwest MinZu University, 2012.

[6] ZhongJinwen, Integrated yugu study in China, Nationalities Publishing House, 2002. 